\title{
3D-ANTLERS: VIRTUAL RECONSTRUCTION AND THREE-DIMENSIONAL MEASUREMENT
}

\author{
S. Barba ${ }^{\text {a, } *, F . ~ F i o r i l l o ~}{ }^{\text {a }}$, E. De Feo ${ }^{\text {a }}$ \\ ${ }^{a}$ Department of Civil Engineering, University of Salerno, Italy - (sbarba, ffiorillo)@unisa.it
}

KEY WORDS: Hand scanner, Photogrammetry, 3D cataloguing

\begin{abstract}
:
The main objective of this paper is to establish a procedural method for measuring and cataloguing antlers through the use of laser scanner and of a 3D reconstruction of complex modeling. The deer's antlers have been used as a test and subjected to capture and measurement. For this purpose multiple data sources techniques have been studied and compared, (also considering low-cost sensors) estimating the accuracy and its errors in order to demonstrate the validity of the process. A further development is the comparison of results with applications of digital photogrammetry, considering also cloud computing software.

The study has began with an introduction to sensors, addressing the underlying characteristics of the technology available, the scope and the limits of these applications. We have focused particularly on the "structured light", as the acquisition will be completed through three-dimensional scanners: DAVID and the ARTEC MH.

The first is a low-cost sensor, a basic webcam and a linear laser pointer, red coloured, that leads to acquisition of three-dimensional strips. The other one is a hand scanner; even in this case we will explain how to represent a 3D model, with a pipeline that provides data export from the "proprietary" to a "reverse engineering" software. Typically, these are the common steps to the two approaches that have been performed in WRAP format: point sampling, manual and global registration, repair normals, surface editing and texture projection. In fact, after a first and common data processing was done with the use of a software supplied with the equipment, the proto-models thus obtained were treated in Geomagic Studio, which was also chosen to allow the homogenization and standardization of data in order to make a more objective comparison.

It is commonplace to observe that the editing of the digital mock-up obtained with the DAVID - which had not yet been upgraded to the 3.5 release at the time of this study - is substantially different. In the ARTEC digital mock-up for example, it shows the ability to select the individual frames, already polygonal and geo-referenced at the time of capture; however, it is not possible to make an automated texturization differently from the low-cost environment which allows to produce a good graphics' definition.

Once the final 3D models were obtained, we have proceeded to do a geometric and graphic comparison of the results. Therefore, in order to provide an accuracy requirement and an assessment for the 3D reconstruction we have taken into account the following benchmarks: cost, captured points, noise (local and global), shadows and holes, operability, degree of definition, quality and accuracy.

Subsequently, these studies carried out in an empirical way on the virtual reconstructions, a 3D documentation was codified with a procedural method endorsing the use of terrestrial sensors for the documentation of antlers.

The results thus pursued were compared with the standards set by the current provisions (see "Manual de medición" of Government of Andalusia-Spain); to date, in fact, the identification is based on data such as length, volume, colour, texture, openness, tips, structure, etc. Data, which is currently only appreciated with traditional instruments, such as tape measure, would be well represented by a process of virtual reconstruction and cataloguing.
\end{abstract}

\section{INTRODUCTION: OBJECT OF STUDY}

The goal of this project was to define a new method to catalogue antlers through the use of three-dimensional measurement that allows the reconstruction of virtual models. As an experimental object of study, properly conserved roe deer antlers were used.

The idea of the project was born within the cooperation agreement between the University of Salerno and the "Grupo de Investigación IGPU” of the Polytechnic School of Cáceres (Dr. José Juan de Sanjosé Blasco) with the support of the Polytechnic School of Algeciras (Engineer Álvaro Montes Domínguez).

One of the main roe deer populated centres of the Iberian Peninsula is found in Montes de Toledo, Sierra Morena, east of the Extremadura and the Andalusian hills of Jaén and Cádiz. Among the Iberian population, there are local differences of size and types of antlers, both depending mainly on the feeding and the health of the animal.

It's important to know the main characteristics of roe deer antlers to reproduce the 3D model and properly identify its parts. Each antler consists of a main beam with a pointy ending, inserted on the bottom through a pedicle, a bony pivot on the skull through a broadening bone called the coronet. Around the first bottom half of the main beam a new tine comes out facing front called the brow tine. On the last third of the beam a second tine comes out facing backwards called the back tine. The main beam ends with a third tine called the top tine. The antler configuration is therefore relatively simple, formed only by a main beam and three tines (Figure 1).

Even though some authors have stated that the excrescence, buttons or lumps present on the antlers called pearling grow larger in quantity as the individual ages, there is no consistent evidence that finds a connection between age and pearling.

\footnotetext{
* Corresponding author.
} 


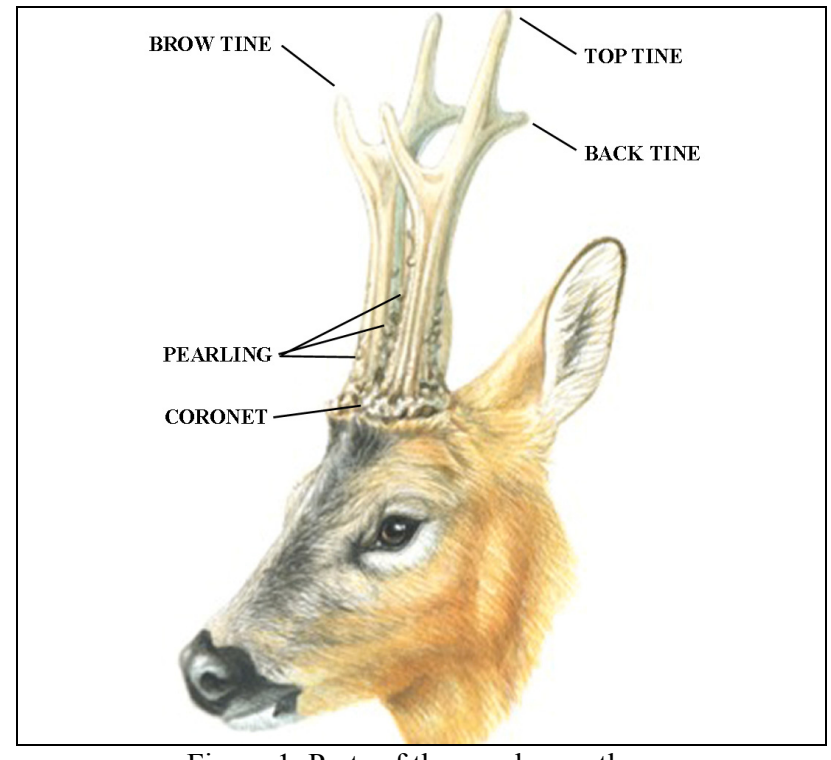

Figure 1. Parts of the roe deer antlers

To add more, the number of pearling is one of the properties that define the "beauty" of trophies during the certification procedure, therefore, the level of detail of the final model needs to allow a better visualization and identification of peculiarities.

For example, according to the "Reglamento de Funcionamiento y Manual Práctico de Medición para la Homologación de Trofeos de Caza de Andalucía" (Andalucía Working Regulation and manual of procedures for Hunting Trophies Certification), the necessary measurements to fill out the "Ficha oficial de Homologacion para Corzo" (Official Sheet for Roe Deer Certification) are weight, volume and beauty. This last one, less objective, is made up by several aspects: colour, number of pearling, coronets dimensions, tines, and scale (maximum distance between each antler)

\section{SURVEY}

For the 3D survey we have bought, studied, and used two data acquisition systems: the low-profile 3D scanner DAVID and the hand-held scanner ARTEC MH. On the one hand, the DAVID is a low-profile scanner provided with a webcam and a linear laser; on the other hand, the ARTEC MH is a highprofile scanner with a light source that is not a laser but a flash type bulb.

The main components of DAVID are three: the high-resolution 2-megapixel webcam (1600 x 1200) with autofocus (Logitech Quickcam 9000 PRO), the red line laser module (Class 1) with adjustable focus and the calibration corner (used to calibrate the camera and to use as a background structure during the scanning, in which the two plain panels must stand in an angle of exactly $90^{\circ}$ ). Besides these components, a managing software called DAVID Laserscanner Professional Edition 2.6.6 is provided. The LC650-16-3-F is a laser module that projects a very thin red laser line with a wavelength of $650 \mathrm{~nm}$. The adjustable focus allows a large range of operations and the large aperture angle of $90^{\circ}$ provides a laser line of $2 \mathrm{~mm}$ with at a distance of $1 \mathrm{~m}$.

The steps followed to scan with DAVID were: setting the scene by adapting the laser module, webcam and calibration corner to the scanned object; orientating and calibrating the webcam; 3D scanning with the linear laser; capturing colour texture (optional); verifying the $3 \mathrm{D}$ image. It was necessary to repeat the last three steps several times to scan the different sides of the object, even if a lower consistency is obtained for the final data. The aligning and composition phase of all the captures can be merged into one single model with the provided software or an alternative one (for example, Geomagic Studio). The final export files formats supported are .obj, .stl or .ply.

First of all, it is important that the object to be scanned is placed in the calibration corner. The area for the markers can be a little bigger than the object itself, which has to be positioned in the centre and as closest to the panels as possible. All these dimensional verifications have to be made before starting the scanning process.

Once the final position of the scene has been set, it is necessary to adjust the camera focus control to get an image as sharp as possible of the object's surface. Throughout this investigation, we found very useful to temporarily activate the automatic focus; this allows you to quickly individualize the best setting. Once the sharpness is set, automatic focus was deactivated. In fact, the focus value must be exactly the same for the calibration, scanning and texture capture. If the value is changed, calibration needs to be repeated.

For the camera calibration it is necessary to temporarily remove the object from the scene to let the webcam have a complete vision of the markers. During this phase, the most important thing is to be careful not to modify the relative position of the webcam and the calibration corner. An advice for this step is to regulate the camera with a very high brightness (preferably setting the exposure at a high value under Advanced in the Camera setting panel), to let the image be overexposed and that all markers are clearly visible with well defined surfaces.

If the calibration wasn't properly made, the restitution of the markers analyzed won't correspond with their real positions. Many times, to recognize them correctly it is necessary to improve brightness and contrast (under Device Settings in the Camera setting panel); in fact, if dark elements appear on the image, the software might detect them as markers by mistake. These mistaken elements must be "masked" to keep them unconsidered in the calibration algorithm.

From this point on, the relative position of the webcam and the calibration corner have to remain fixed in position. Before starting to scan, it is necessary to project the laser line over the object and regulate the ray to make it as thin and sharp as possible (to clarify, the thinness of the laser line changes relatively to its distance from the object). The webcam must be regulated to make the image very dark and let only the red laser line to remain visible.

During the 3D scanning phase, it is important to let the line over the object move slowly and symmetrically. One very slow accurate scan of the laser is much better than many frequent scans of different direction. Only small holes from the scan can be automatically filled afterwards.

In this process, texture captures have also been made to obtain a coloured 3D model. For that purpose, a different camera settings from the 3D scanning process is necessary, regulating the webcam to get a well illuminated image (it is extremely important that the focus value remains always the same). To accomplish that, a homogeneous illumination is required: day light without direct sunlight incidence, diffuse illumination in every direction, and no point-shaped radiation.

What we've concluded from working with images with DAVID is that the webcam parameters influence very noticeably the final results. Good models can only be obtained with a lot of experience in managing the settings correctly.

In fact, the optimum settings for the webcam depend on several factors: the colour and properties of the object's surface, the room ambient illumination, the size, etc. 
Therefore, for each scan of antlers, different settings need to be made and cannot be automatically set; furthermore, the settings are essentially very different for each one of steps: webcam calibration, 3D scanning and texture capture. Nevertheless, if the established values before each phase are correctly memorized, it is possible to go from one function to the other without having to adapt the settings every time.

For example, for the calibration phase it might be very useful to set a high contrast value and a very high exposure value (this will regulate how much time the webcam will expose each frame). The purpose for this is to obtain a very clear and uniform image in which the black calibration markers stand out. On the other hand, for the scanning phase it might be better to set a minimum exposure value $1 / 500$ s (due to a malfunctioning error of the webcam software, the $1 / 1000 \mathrm{~s}$ should not be used); the purpose of this is to obtain an image as dark as possible (almost black), in which only the laser line appears and not very brightly. Several experimental tests have allowed us to point out one of the most important settings to take into account and also some recommendations about the configuration parameters. Also, we recommend not to use Zoom (setting it to $100 \%$ ) and turning off the "Face detection" function.

On the other hand, the parameters of the image output size allow us to choose a scanning resolution: the higher the value, the higher the detail; this will, of course, increase the processing time. For the first test scan, a $640 \times 480$ resolution is advised, but changing the resolution forces us to recalibrate the camera. It is advised to choose the highest frame rate allowed for the chosen image size.

One of the most obvious advantages of this device is the quality-price ratio. On practice, it has been proven that experience and correct handling of webcam parameters are very important to obtain good results.

The second data gathering of the antlers was developed with the ARTEC MH, a portable device that stands out for its light weight and compact size. The MH (Medium Hand-held) has a working distance between 0.4 and 1 metre, around average compared to other ARTEC scanners. The closest linear field of view is $214 \times 148 \mathrm{~mm}$, while the furthest is $536 \times 371 \mathrm{~mm}$. The capture system is made by a camera, a flash bulb that emits a light pattern. The distortion of this pattern over the object's uneven surface is translated into a $3 \mathrm{D}$ image through the ARTEC software.

That pattern is projected at up to $15 \mathrm{fps}$ (the newer model works at up to $16 \mathrm{fps}$ ), therefore it is also possible to move around the object quickly and still obtain good results. Furthermore, its use does not require special markers to be put on the scanned object.

Unlike the DAVID scanner, the ARTEC MH system does not have the ability to capture texture or produce colour scans. It guarantees a 3D resolution of up to $0,5 \mathrm{~mm}$ and a $3 \mathrm{D}$ point accuracy of up to $0,1 \mathrm{~mm}$ and an acquisition speed of up to 288.000 points/s.

Through the use of its management software, the first data from the captures was processed, like verifying the visual frames (eventually deleting the ones with errors). After this, each scan was saved as a .obj file, the same export file chosen with the DAVID.

\section{DATA PROCESSING}

To work under the same conditions and make a more objective comparison, the post-processing phase was developed with the same software, Geomagic Studio 2012.

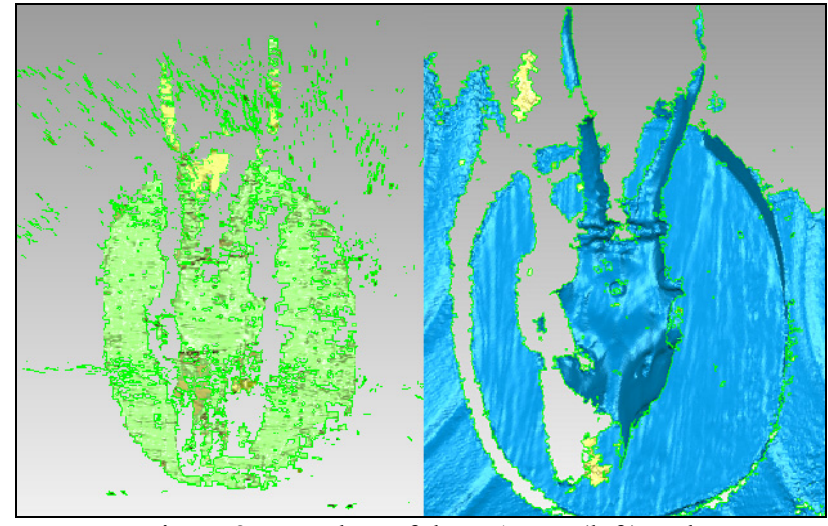

Figure 2. Raw data of the DAVID (left) and the ARTEC MH (right)

The software provided by each laser manufacturer was only used for preliminary editing and export. In general, in both cases the same steps were followed for the data processing up to the reconstruction of a 3D model (Guidi et al., 2010):

1. Data filtering and noise reduction;

2. Manual registration, to align different scan using homologous points;

3. Global registration by automatic alignment algorithms;

4. Merging different scans into a single polygonal model;

5. Surface editing - manual and automatic - to correct possible errors and imperfections of the generated mesh (corrupted triangles, duplicate triangles, nonmanifold edges, non-manifold vertices, etc.);

6. Filling holes left on the model (working according to the curvature around the hole to adapt, as accurate as possible, the new mesh surface to the shape of the object).

There is also a following phase, phase 7, only for the colour treatment of the ARTEC MH model. In fact, this isn't necessary for the merged model of the DAVID since a texture map is created based on the colour information of each scan (the scans are matched with the images captured by the webcam, therefore this information is already loaded onto the model). On the contrary, the ARTEC MH has no texture capturing device. The colour information is therefore loaded in a new step projecting photo shoots over the digital model. These pictures were taken with an 8 megapixels camera over a black background making 4 lateral takes on each side and 2 front and back takes. The important thing about the background is that it must be consistent in order to contrast with the object more evenly.

For the photo projection on the mesh surface it is necessary to proceed detecting homologous points on the photo and the model. The position of the corresponding points is very important: the best thing is to find natural markers well distributed around the object, on the sides and centre, to make a better framed texture (Barba et al., 2011).

During the data processing phase we realized that the DAVID has, at first, a higher noise level (Figure 2) and a bigger number of holes on the model surface, making $3 \mathrm{D}$ reconstruction a longer and more complex process (Giordano et al., 2012).

\section{METHOD COMPARISON}

From our first observations and comparing the data processing on both scanners and the obtained virtual models, we developed a comparative chart also taking into account 
other aspects of the scanners. Among some of the advantages found on the ARTEC MH, the possibility of scanning the antlers in one take is a very useful option, surrounding the antlers and analyzing them from different sides and angles. This, in fact, places a great advantage over the DAVID which that forces us to work in a Lab, keeping a constant angle of approximately $30^{\circ}$

On the other hand, the DAVID scanner comes with a webcam that automatically captures the texture of our model, embedding it directly to the 3D model. This assumes a great advantage to automatically apply texture but the low resolution of this camera limits its possibilities. Furthermore, the pictures taken with an external camera that are then applied to the model generated by the ARTEC MH present a much higher resolution (Figure 3 ).

Regarding the points cloud, the ARTEC MH features a precision four times higher than the DAVID.

Despite all that, the biggest difference resides on the price of the scanners: the ARTEC MH costs around twenty times more than the DAVID.

On the next chart (Table 1), we present a summarized comparison of the most relevant characteristics of each one of the used scanners.

Comparing both models, the first thing that stands out is that the metric proportions are equal, but the model scanned with the DAVID, despite its texture treatment, still presents a surface with a noticeable level of noise. As a matter of fact, at first glance, the model developed with the ARTEC MH shows a sharper and more consistent model. This is also due to the higher quantity of points the ARTEC scanner is able to obtain, providing a higher resolution, less noise, and an important reduction of holes that lack metric information. The latter is of particular importance since it allows us to save plenty of time in the data processing phase and also guarantees a higher precision of the virtual model in comparison to the real model.

On the contrary, the model developed with the DAVID presents a huge amount of holes and, due to its big size, this makes it almost impossible to fix. This proves that the use of this instrumentation is better for simple and flat objects and not for objects with such complex surfaces, such as the ones used for this project.

\begin{tabular}{|c|c|c|}
\hline & ARTEC MH & DAVID \\
\hline Light source & flash bulb & laser \\
\hline Working angle & indifferent & $\sim 30^{\circ}$ \\
\hline $\begin{array}{l}\text { 3D point } \\
\text { accuracy up to }\end{array}$ & $0,1 \mathrm{~mm}$ & $0,4 \mathrm{~mm}$ \\
\hline Range & $0,4-1 \mathrm{~m}$ & $0,3-0,8 \mathrm{~m}$ \\
\hline $\begin{array}{l}\text { Accuracy } \\
\text { over the distance }\end{array}$ & up to $0,15 \%$ & up to $1 \%$ \\
\hline $\begin{array}{l}\text { Ability to } \\
\text { capture texture }\end{array}$ & no & yes \\
\hline Texture resolution & - & $2 \mathrm{Mp}$ \\
\hline $\begin{array}{l}\text { Computer } \\
\text { requirements }\end{array}$ & $\begin{array}{c}\text { 8Gb RAM, } \\
\text { 3D graphics card } \\
\text { (NVIDIA } \\
\text { GeForce 9000) }\end{array}$ & $\begin{array}{c}1 \text { GB RAM, } \\
\text { 3D graphics card } \\
\text { (NVIDIA GeForce } \\
\text { or ATI Radeon) }\end{array}$ \\
\hline Price & $\begin{array}{c}10.000 € \\
\text { (approximately) }\end{array}$ & $\begin{array}{c}500 € \\
\text { (approximately) }\end{array}$ \\
\hline $\begin{array}{l}\text { Triangles } \\
\text { of the final model }\end{array}$ & 246.000 & 370.000 \\
\hline
\end{tabular}

Table 1. Specifications comparison
Furthermore, we couldn't manage to completely close the DAVID model due a great amount of surface holes on the rear of the antlers (Figure 4). To compare the surface bumps on each model, a DEM analysis was made to detect deviations from a plane of reference (Figure 5). Another comparison was made analyzing deviations of the DAVID model in relation to the ARTEC model (Figure 6). We can observe a maximum difference of $\pm 10 \mathrm{~mm}$ (although what is relevant is the small percentage of triangles seen on the histogram) and a maximum distribution value in the range of $\pm 1 \mathrm{~mm}$.

The analysis was then taken further, setting $\pm 1 \mathrm{~mm}$ as the threshold for maximum and minimum deviations to clarify and estimate the level of noise on the second surface (Figure 7). This left clear evidence that both models present a big difference in surface roughness: the one by the ARTEC MH presented a much more accurate and uniform surface.

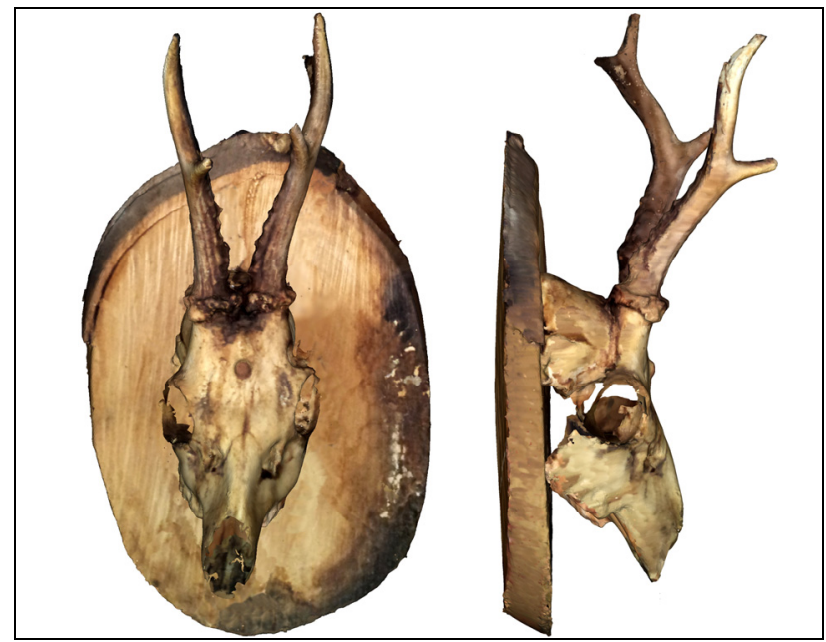

Figure 3. Textured 3D model

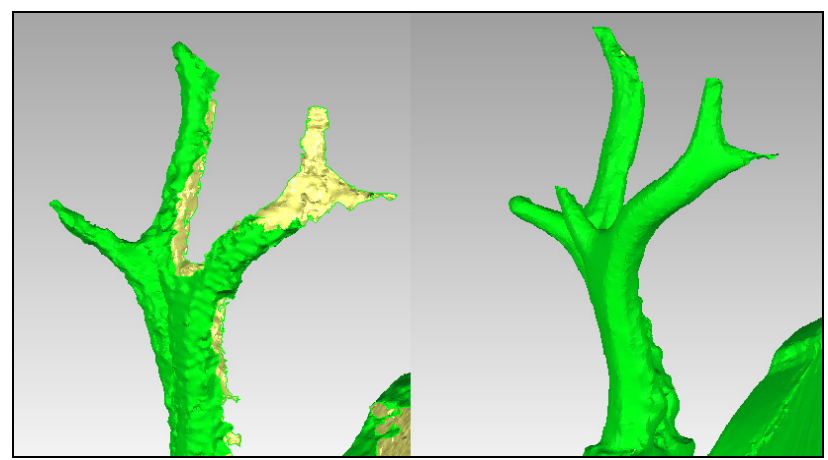

Figure 4. Holes on the models of the DAVID (left) and the ARTEC MH (right)

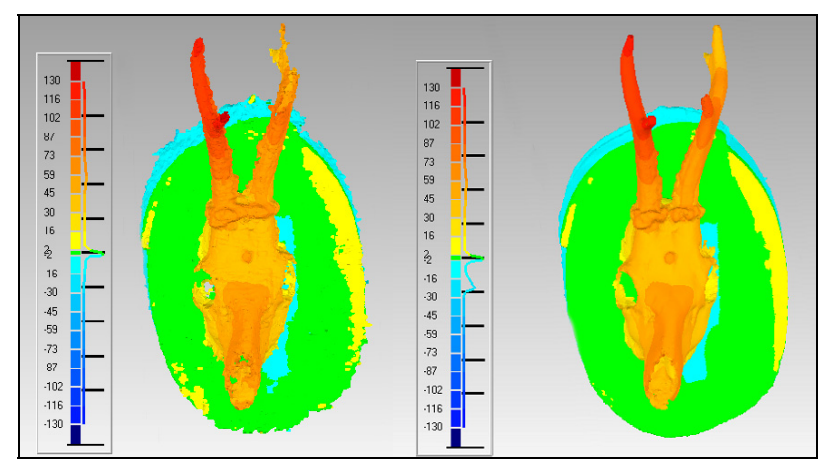

Figure 5. DEM comparison of the DAVID (left) and the ARTEC MH (right) 


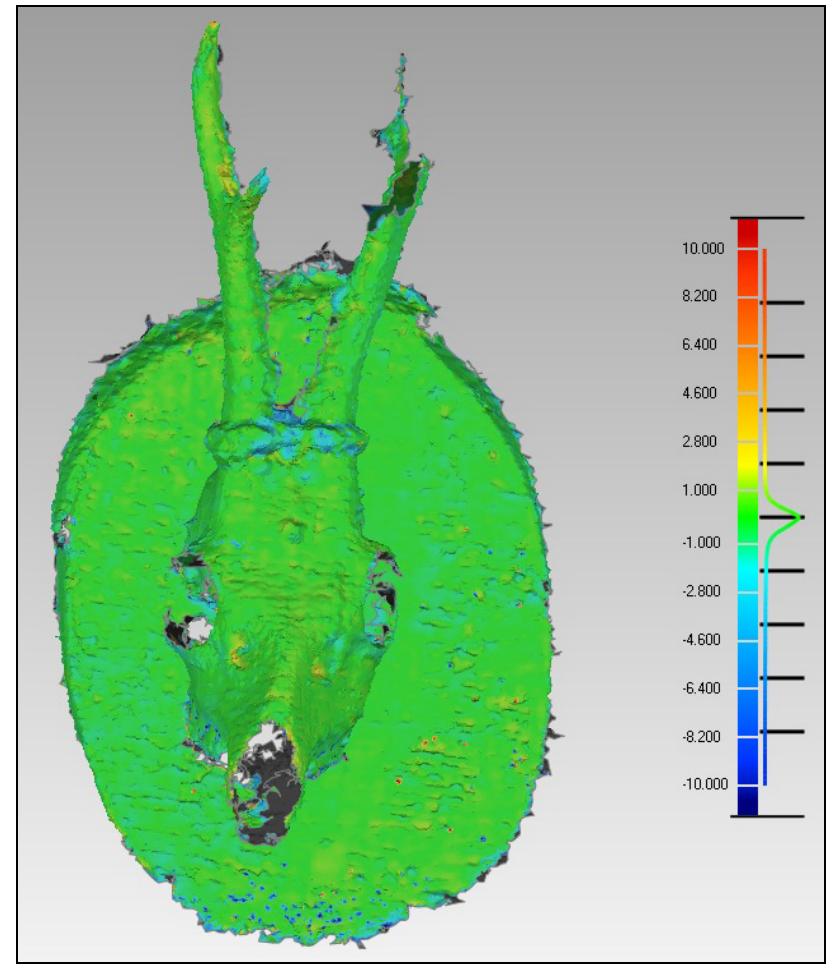

Figure 6. Deviations comparison of the DAVID model to the ARTEC model, threshold $\pm 10 \mathrm{~mm}$

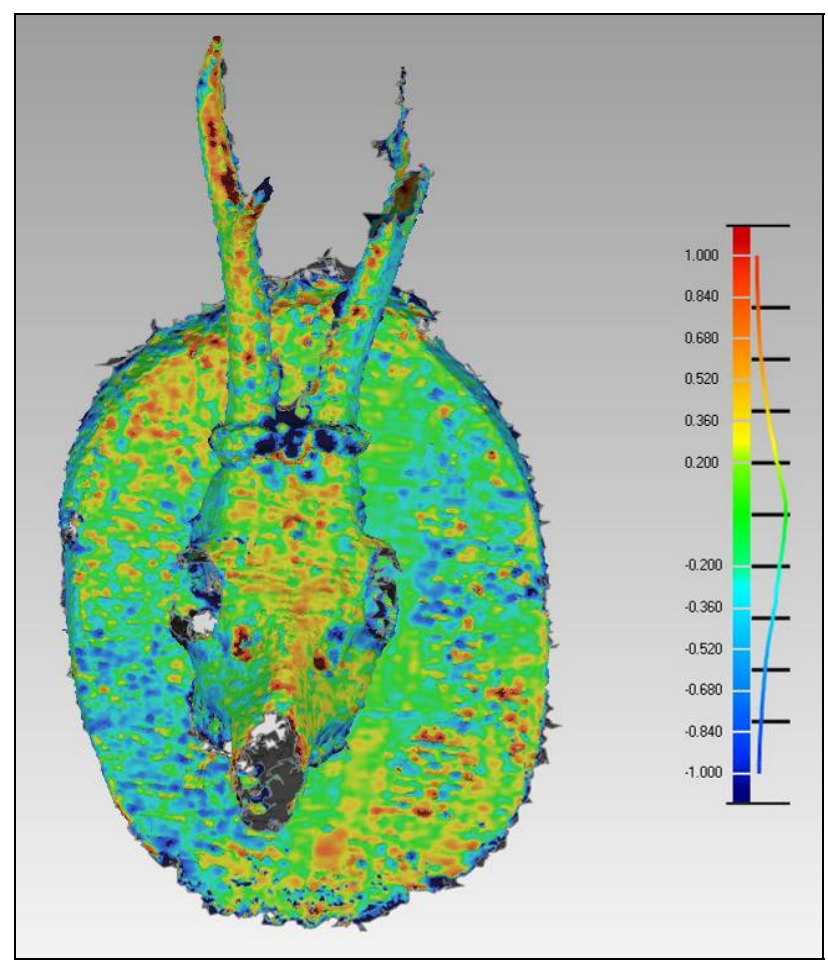

Figure 7. Deviations comparison of the DAVID model to the ARTEC model, threshold $\pm 1 \mathrm{~mm}$

\section{ANTLERS CATALOGUING}

After analyzing the 3D models we proceeded to catalogue the roe deer antlers, following the "Reglamento de Funcionamiento y Manual Práctico de Medición para la Homologación de Trofeos de Caza de Andalucía" (Andalucía Working Regulation and Manual of Procedures for Hunting Trophies Certification).

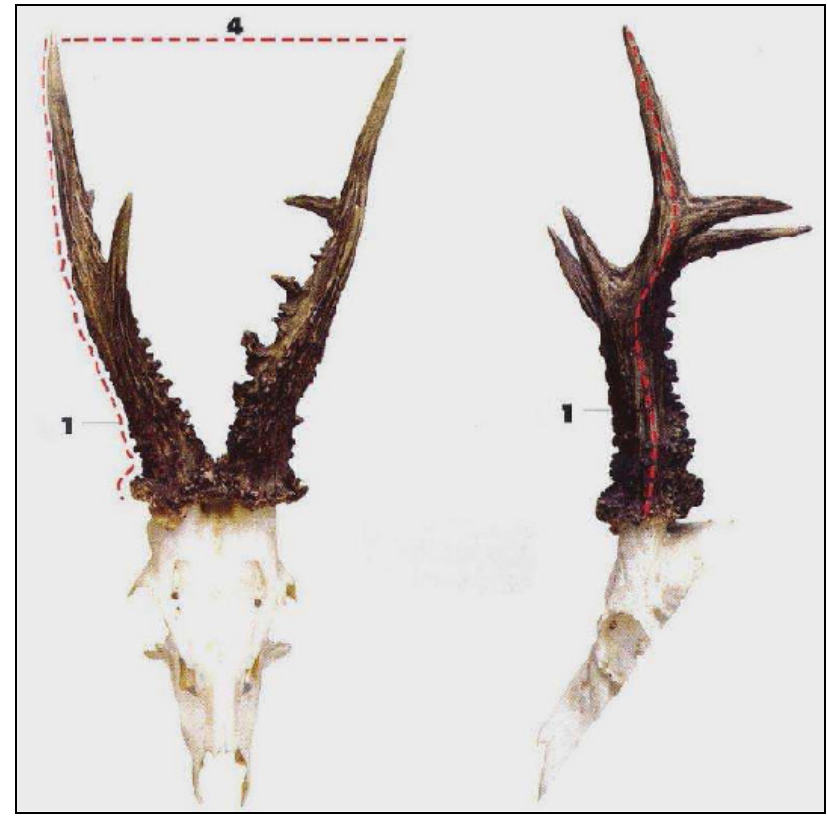

Figure 8. Antlers measuring method ("Reglamento de Funcionamiento y Manual Práctico de Andalucía”)

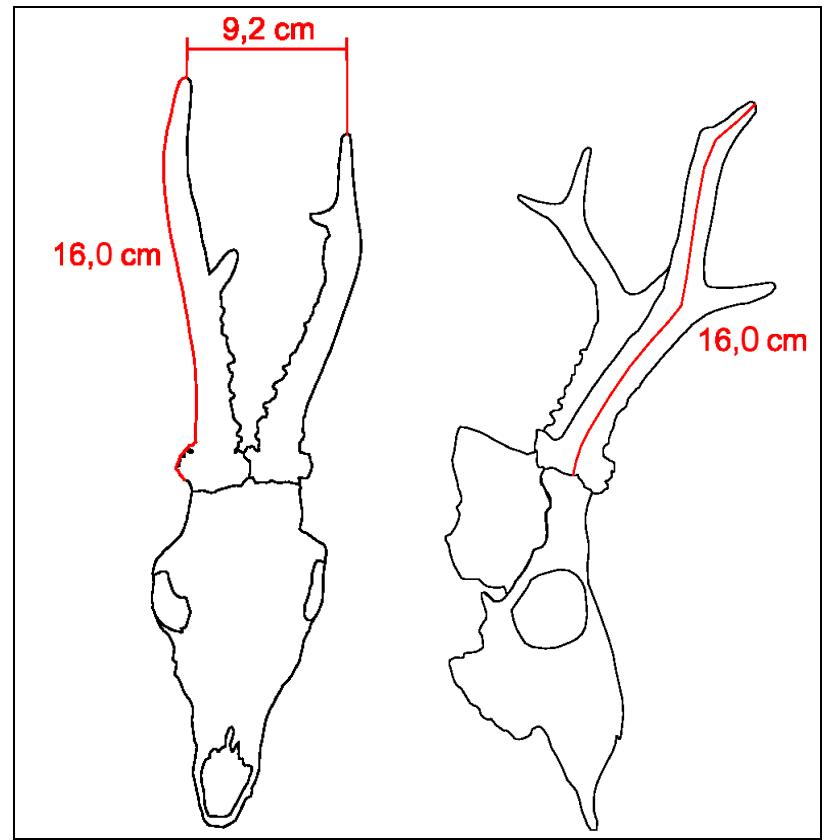

Figure 9. Antlers length and scale measured with the conventional tape

This study centred only on the characteristics that require measurements (length, scale, weight and volume of the antlers) and not on the more subjective features (such as colour and pearling), even when these qualitative factors can be obtained from a digital textured model.

As stated on the Regulation, the length of the antler must be measured with a tape, following the exterior curvature from the bottom edge of the coronet to the tip of the high tine, pressing the tape against the antler 2 or 3 centimetres from the coronet, not taking into account its abnormalities (Figure 8). Measuring the antler with the conventional methods, we obtained a result of approximately $16,0 \mathrm{~cm}$ (Figure 9).

Afterwards, the same measurement was made on the 3D model with the Geomagic Qualify software, obtaining a final result of $16,07 \mathrm{~cm}$ (Figure 10). 


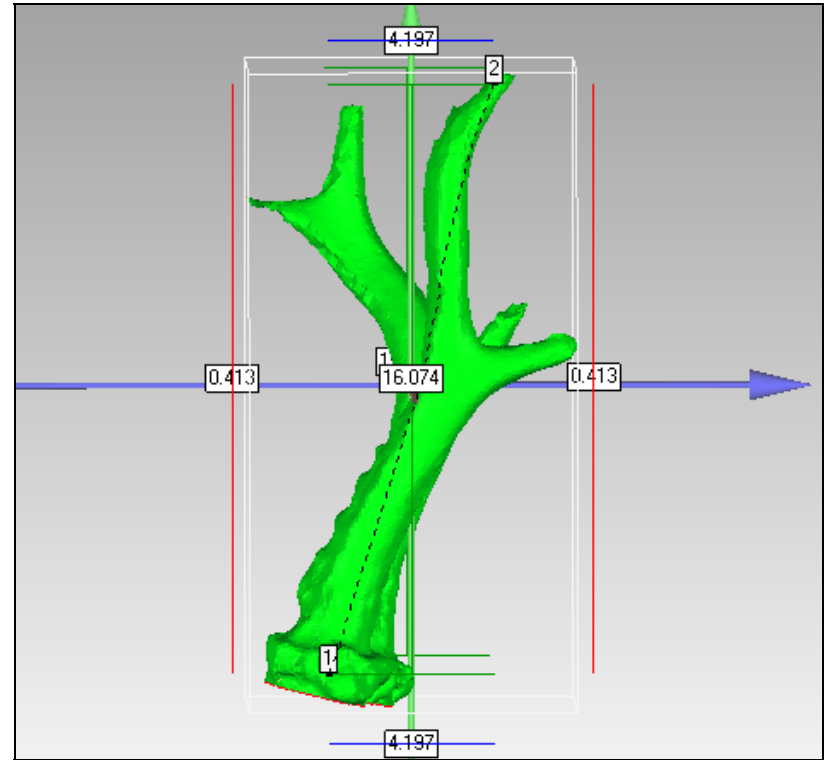

Figure 10. Antler length measurement on the 3D model

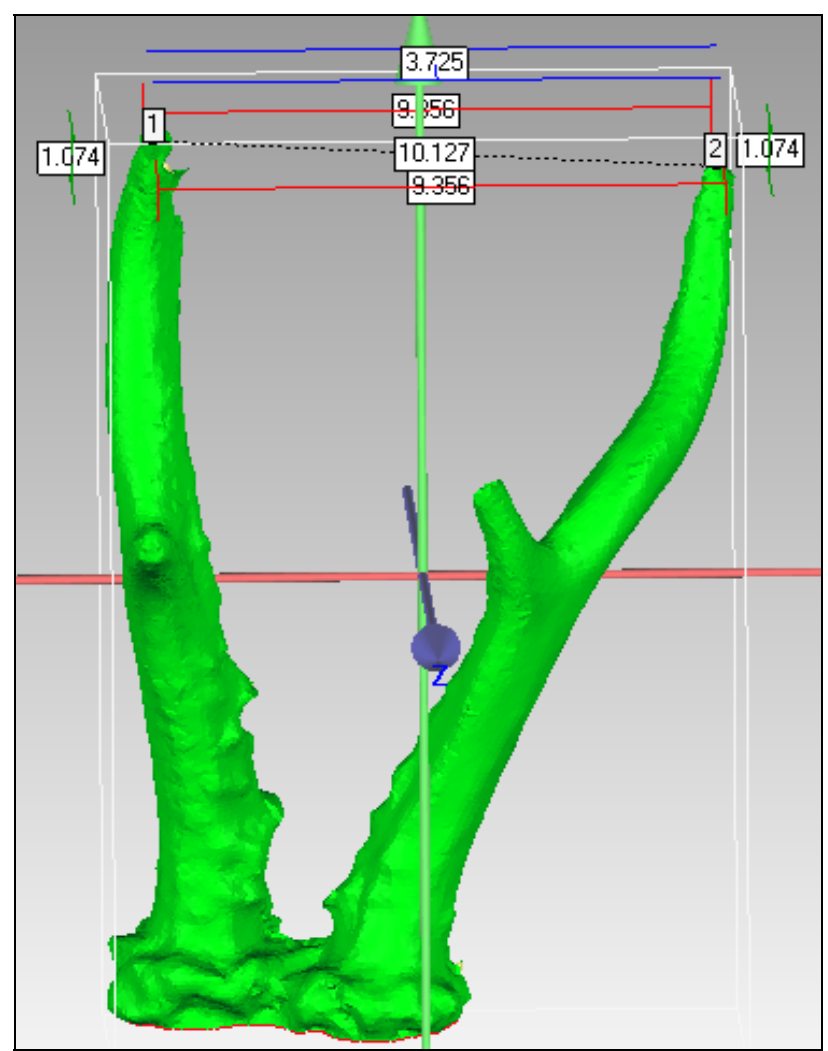

Figure 11. Antlers scale measurement on the 3D model

The scale of the antlers refers to the maximum interior distance. The measurement made with the tape gave as an approximate result of $9,0 \mathrm{~cm}$. On the other hand, the 3D model gave us an exact value of $9,36 \mathrm{~cm}$ (Figure 11).

Traditionally, the antlers volume is obtained submerging on the water only the antlers down to the coronet, also included. Afterwards, with the initial and final volume difference we're able to obtain the antlers volume in cubic centimetres. It is also possible to use a hydrostatic balance. Instead, to calculate the volume on the 3D model, we isolated the antlers, coronet included, and we closed the bottom part with a plane; having a completely closed model, we were able to calculate the volume obtaining a result of $66,2 \mathrm{~cm}^{3}$.
In short, the reliability, integrity and quickness of the metric information obtained from the virtual reconstruction allow us to support the advantages and precision of three-dimensional measurement.

\section{CONCLUSIONS}

After finishing this study we can certainly say that both instruments are useful when the purpose is measuring an object for mere cataloguing. We have to consider, nonetheless, the negative aspects of using the DAVID: the data acquisition phase is quite difficult since you can not rotate the scanner around the object; the measurement is less accurate, although enough to reach the precision required by the cataloguing system. These disadvantages of the DAVID are, however, compensated by the low cost of the device, which makes them almost irrelevant if considering the much higher cost of its alternative, the ARTEC MH. Regardless, if you want to obtain any qualitative information about the "beauty" of the antlers such as identifying and numbering the pearling (whose dimensions are quite small) the use of the ARTEC MH would become necessary since it provides much more detail.

To conclude, these practices are the state of the art so naturally, the choice of techniques and technologies, the procedures followed, and the final results are usually conducted by a method often fragmented and without scientific criteria (Remondino et al., 2011). These laboratory tests are mainly aimed to contribute to the encoding and establishment of new operational methods, new guidelines for the survey and virtual reconstruction of small and medium sized objects.

\section{REFERENCES}

Junta de Andalucia, Consejeria de Medio Ambiente. "Reglamento de Funcionamiento y Manual Práctico de Medición para la Homologación de Trofeos de Caza de Andalucía", http://www.juntadeandalucia.es/medioambiente/web/1_consejeria _de_medio_ambiente/dg_gestion_medio_natural/instituto_andalu Z_de_la_caza_y_la_pesca_continental/homologacion_trofeos_caz a/manual_medicion_homologacion_trofeos.pdf (31 Jen. 2013).

Guidi G., Russo M., Beraldin J., 2010. Acquisizione $3 D e$ modellazione poligonale. McGraw-Hill, Milano.

Barba S., Fiorillo F., Ortiz Coder P., D’Auria S., De Feo E, 2011. An application for cultural Heritage in Erasmus Placement. Surveys and 3D catologuing archaeological finds in Mérida (Spain). In: International Archives of Photogrammetry, Remote Sensing and Spatial Information Sciences, Trento, Italia, Vol. XXXVIII-5/W16.

Giordano M, Barba S., 2012. Le Geometrie del decoro architettonico. Sistemi di presa scanning $3 D$ e prototipazione. CUES, Salerno.

Remondino F., 2011. Heritage Recording and 3D Modeling with Photogrammetry and 3D Scanning. Remote Sensing, 3(6), pp. 1104-1138.

\section{ACKNOWLEDGEMENTS}

Special thanks to Francisco Ferraris of the University of Córdoba (Argentina). 